\title{
UAV Monitoring of Excavation Works
}

\author{
Roman Shults (D) ${ }^{*}$, Khaini-Kamal Kassymkanova ${ }^{2}$, Shugyla Burlibayeva ${ }^{3}$, \\ Daria Skopinova $^{4}$, Roman Demianenko ${ }^{5}$, Yurii Medvedskyi ${ }^{6}$ \\ 1, 4, 5, ${ }^{6}$ Department of Engineering Geodesy, School of GIS and Land Management, \\ Kyiv National University of Construction and Architecture, Kyiv, Ukraine \\ ${ }^{2,3}$ Department of Cartography and Geoinformatics, Faculty of Geography and \\ Environmental Sciences, Al-Farabi Kazakh National University, Almaty, Kazakhstan
}

Received 27 February 2020; accepted 3 March 2020

\begin{abstract}
The first stage of any construction is carrying out excavation works. These works are high-priced and timeconsuming. Mostly, for geodetic control of the works, the surveyors are using total stations and GNSS equipment. Last decade, UAV technology was a breakthrough in the geodetic technologies market. One of the possible applications of UAV is the monitoring of excavation works. In the article, the opportunities and accuracy of UAV data while performing the excavation works were studied. The surveying of earth volume in the middle of construction works was made using DJI Phantom 4 UAV. The data were being processed using two photogrammetric software: Agisoft Metashape and PhotoModeler Premium. For comparison, the surveying also was made using a conventional total station. For each data source, the 3D models were generated. The obtained models were compared with each other in CloudCompare software. The comparison revealed the high accuracy of UAV data that satisfies customer's requirements. For the case of two software comparing, it is better to process data using PhotoModeler. The PhotoModeler software allows performing in-depth data analysis and blunders searching.
\end{abstract}

Keywords: unmanned aerial vehicles, geospatial monitoring, 3D modeling, excavation works, volumes.

\section{Introduction}

To date, UAV aerial photography has become widespread. UAVs are used to solve mapping, monitoring, inventory, and specialized military tasks (Sadikin et al., 2019; Hao et al., 2016; Henriques et al., 2016; Isola et al., 2015; Sadikin et al., 2014). This technology has gained considerable popularity among surveyors and photogrammetrists when creating topographic maps using aerial photography for small areas. One of the time-consuming engineering tasks is excavation works monitoring and volumes determination. Conventionally, this task is being solved by total stations or close-range photogrammetry. To date, scant attention has been paid to UAVs application for that surveying. Due to its features, UAV takes a niche between traditional aerial photography and terrestrial topographic surveying. The main feature and difference between UAV surveying and conventional aerial photography is its data quality. Limited dimensions and low technical properties of UAVs (Colomina \& Molina, 2014) do not allow installing high-quality navigation systems and cameras. Therefore, the quality of UAV data is much worse than aerial photography. When surveying by UAV, unlike conventional aerial photography, one has to take into account a large number of additional conditions, including the state of the atmosphere, the possible variation of height and speed, operating time, aerodynamic characteristics of UAVs, etc. The most detailed overview of all factors and their calculation is given in (Bosak, n.d.). UAV data have significant inclination angles and violated geometry of paths compared to aerial photography that is often not consistent with the previous project. These drawbacks, in turn, require the use of not only rigorous processing methods but also the involvement of robust processing methods (Ai et al., 2015). On the other hand, digital cameras collect imageries with high frequency and redundancy. These data may be processed automatically by the state-of-the-art software, name a few: Pix4D, Photomod, Capture Reality, Agisoft Metashape, iWitness, PhotoModeler, etc. The rigorous automatic processing methods are deployed in the mentioned software. However, different companies use different mathematical models and approaches. That is why it is badly needed to carry out the study of the software. The last few years have seen an increased interest in the accuracy of UAV data (Mostafa, 2017). Existing studies have focused on the camera quality or the accuracy of navigation data but failed to explore the accuracy of UAV data for particular engineering tasks. This study was carried out to examine both the accuracy of UAV data for the monitoring of excavated ground volumes and the

${ }^{*}$ Corresponding author. E-mail: shultsrv@gmail.com

\section{Copyright (C) 2020 The Author(s). Published by VGTU Press}

This is an Open Access article distributed under the terms of the Creative Commons Attribution License (http://creativecommons.org/licenses/by/4.0/), which permits unrestricted use, distribution, and reproduction in any medium, provided the original author and source are credited. 
quality/reliability of software. Two software PhotoModeler and Agisoft Metashape were chosen for testing. The paper is organized into four main parts, the first of which deals with data gathering, parts two and three both examine different software, the fourth part focuses on analysis and comparison the data gained by software.

\section{Data gathering}

The site of construction works for warehouses has been chosen as a testing region. The data for the study were collected through the use of DJI Phantom 4 UAV. Before the UAV surveying, the coordinates of six GCP were determined in national coordinate system SK-63 using GNSS observations in RTK mode. The horizontal accuracy was estimated at $15 \mathrm{~mm}$ and vertical accuracy $20 \mathrm{~mm}$. By default, the geographic coordinate system was used for imageries referencing. In what follows, these coordinates were used for coarse imageries orientation. The primary surveying parameters are given in Table 1.

Table 1. Surveying parameters

\begin{tabular}{|l|c|c|}
\hline \multicolumn{1}{|c|}{ Parameter } & Value & Notes \\
\hline Number of imageries & 123 & Testing area \\
\hline Surveying height, $\mathrm{m}$ & 85 & Testing area \\
\hline Surveying area, $\mathrm{km}^{3}$ & 0.109 & Testing area \\
\hline Principal distance, $\mathrm{mm}$ & 8.8 & Camera \\
\hline Resolution, $\mathrm{pix}$ & $4864 \times 3648$ & Camera \\
\hline Pixel size, $\mu \mathrm{m}$ & $2.61 \times 2.61$ & Camera \\
\hline
\end{tabular}

In Figure 1 the orthophoto with marked GCPs is presented.

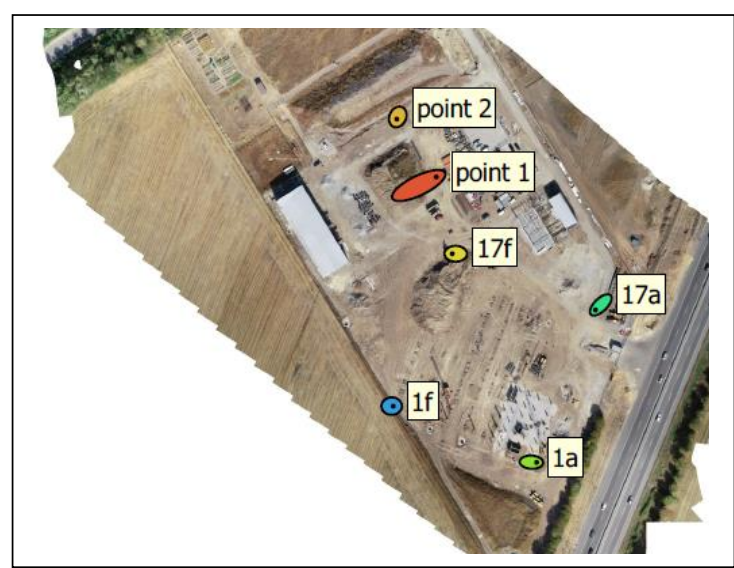

Figure 1. The picture of the testing area with GCPs

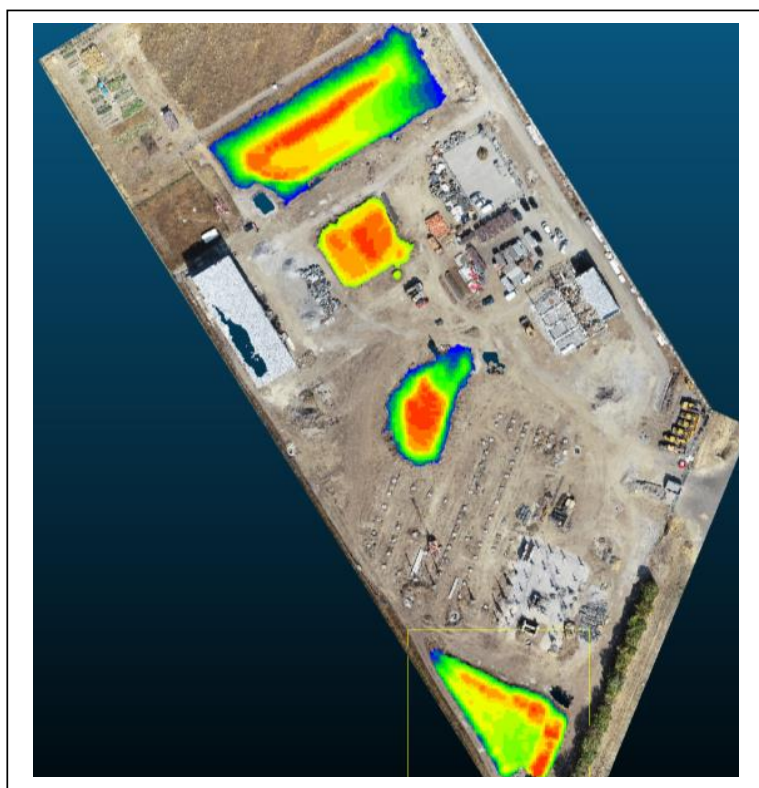

Figure 2. The scheme of testing places location

Four testing places have been chosen on the construction site. The location of these places is shown in color in Figure 2.

The next two sections deal with the data processing and volumes calculation.

\section{Data processing: Agisoft Metashape}

The first software that has been tested was Agisoft Metashape. The gathered imageries were uploaded to the software workspace. The UAV camera was set as uncalibrated. The approximate coordinates of photo centers in the global geodetic coordinate system were used for coarse imageries orientation. Then, the precise orientation by GCPs in a local coordinate system was carried out. The accuracy of the orientation is presented in Table 2. 
Table 2. Accuracy of Agisoft Methashape processing

\begin{tabular}{|c|c|c|c|c|c|}
\hline Axis & $m_{X}, \mathrm{~mm}$ & $m_{Y}, \mathrm{~mm}$ & $m_{Z}, \mathrm{~mm}$ & $m_{H}=\sqrt{m_{X}^{2}+m_{Y}^{2}}, \mathrm{~mm}$ & $m_{P}=\sqrt{m_{X}^{2}+m_{Y}^{2}+m_{Z}^{2}}, \mathrm{~mm}$ \\
\hline Value & 48 & 25 & 47 & 54 & 72 \\
\hline
\end{tabular}

One may notice that the presented accuracy is three times lower than the accuracy of GNSS measurements. These values point out existing not accounted errors in photogrammetric data. Presumably, one of the reasons is the uncalibrated camera. Despite the self-calibration procedure, there is a significant systematic error, as long as most deviations have positive values.

After the adjustment procedure, the 3D model has been generated (Figure 3).

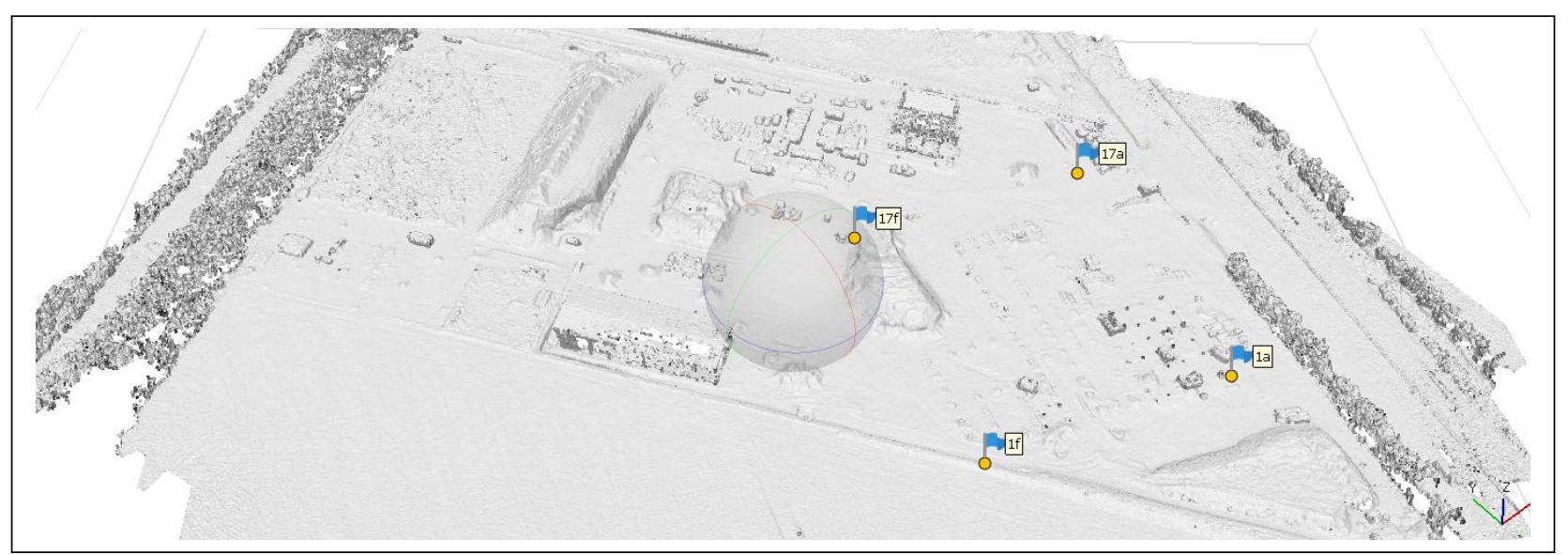

Figure 3. The view of the 3D model generated by Agisoft Metashape

In what follows, the TIN-model and solid model were generated. The total statistic of data processing is presented in Table 3.

Table 3. Outputs of processing

\begin{tabular}{|l|c|}
\hline \multicolumn{1}{|c|}{ Output } & Meaning \\
\hline Resolution, m/pix & 0.46 \\
\hline Points density, points $/ \mathrm{m}^{2}$ & 4.7 \\
\hline Point cloud, points & 224092 \\
\hline Dense point cloud, points & 14695324 \\
\hline Polygons number, polygon & 2939064 \\
\hline
\end{tabular}

These data were used for the comparison and analysis in Section 4.

\section{Data processing: PhotoModeler}

The other software that has been tested was PhotoModeler. As in the previous case, the data set was uploaded to the software workspace. The UAV camera was set as uncalibrated with a self-calibration option. The approximate coordinates measured by the on-board GNSS were used for coarse imageries orientation. The coordinates of GCPs were measured on imageries, and their precise coordinates were inputted to perform bundle adjustment in a local coordinate system. The accuracy of the orientation is presented in Table 4.

Table 4. Accuracy of PhotoModeler processing

\begin{tabular}{|c|c|c|c|c|c|}
\hline Axis & $m_{X}, \mathrm{~mm}$ & $m_{Y}, \mathrm{~mm}$ & $m_{Z}, \mathrm{~mm}$ & $m_{H}=\sqrt{m_{X}^{2}+m_{Y}^{2}}, \mathrm{~mm}$ & $m_{P}=\sqrt{m_{X}^{2}+m_{Y}^{2}+m_{Z}^{2}}, \mathrm{~mm}$ \\
\hline Value & 20 & 13 & 28 & 24 & 37 \\
\hline
\end{tabular}

The presented accuracy almost complies with the accuracy of GNSS measurements. After the adjustment procedure, the 3D model has been generated (Figure 4). 


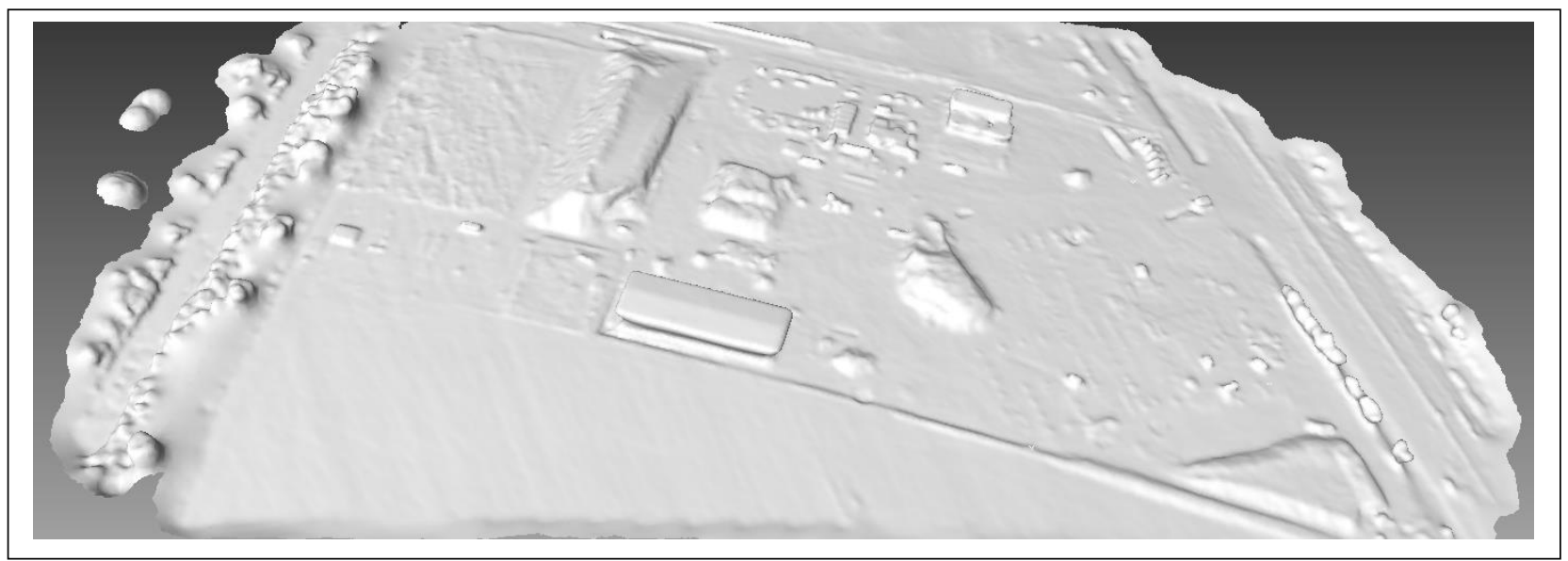

Figure 4. The view of the 3D model generated by PhotoModeler

In what follows, the TIN-model and solid model were generated. The total statistic in PhotoModeler processing is presented in Table 5.

Table 5. Outputs of processing

\begin{tabular}{|l|c|}
\hline \multicolumn{1}{|c|}{ Output } & Meaning \\
\hline Resolution, $\mathrm{m} /$ pix & 1.12 \\
\hline Points density, points $/ \mathrm{m}^{2}$ & 2.0 \\
\hline Point cloud, points & 69432 \\
\hline Dense point cloud, points & 6072016 \\
\hline
\end{tabular}

The 3D model was used for the comparison and analysis in Section 4.

\section{Data comparison}

The comparison of two 3D models has been made using CloudCompare software. Four testing areas were cut on both models and overlaid with each other. The contour maps of those areas are presented below in Figures 5 to 8 .

Using CloudCompare were calculated the volumes of testing areas and found the differences of these volumes:

$$
\Delta V=V_{\text {Photo }}-V_{\text {Agisoft }} \leq 4 \% .
$$

We may treat these differences $\Delta V$ as volume errors. For excavation works, there is a common requirement that the error in volume determination should not exceed $4 \%$. According to this demand, the calculated volumes have compiled in Table 6, and the volume error has estimated.

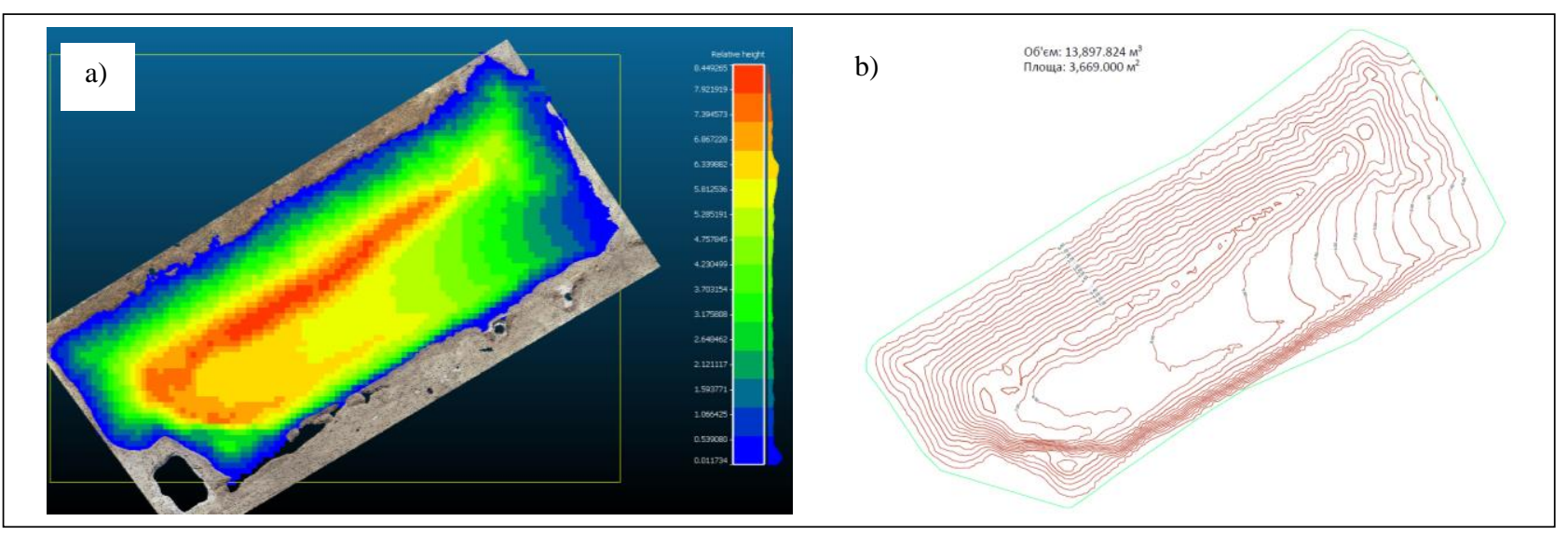

Figure 5. Testing area S1: a) 3D models overlaying; b) contour map 


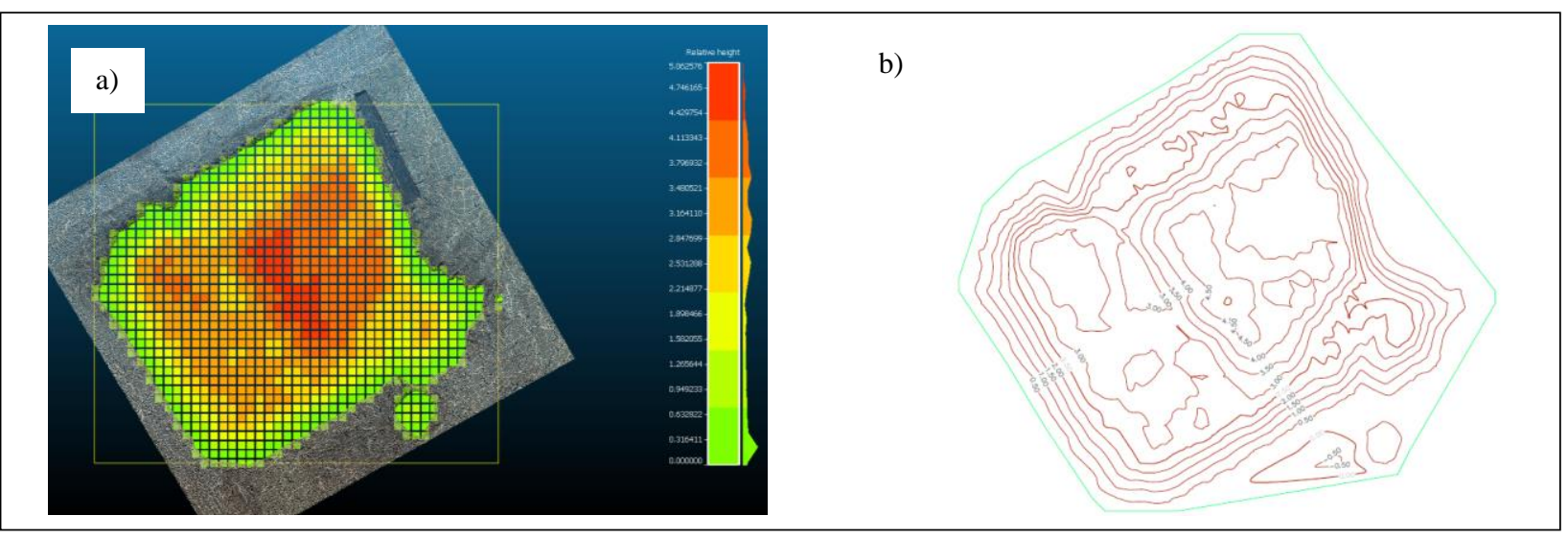

Figure 6. Testing area S2: a) 3D models overlaying; b) contour map

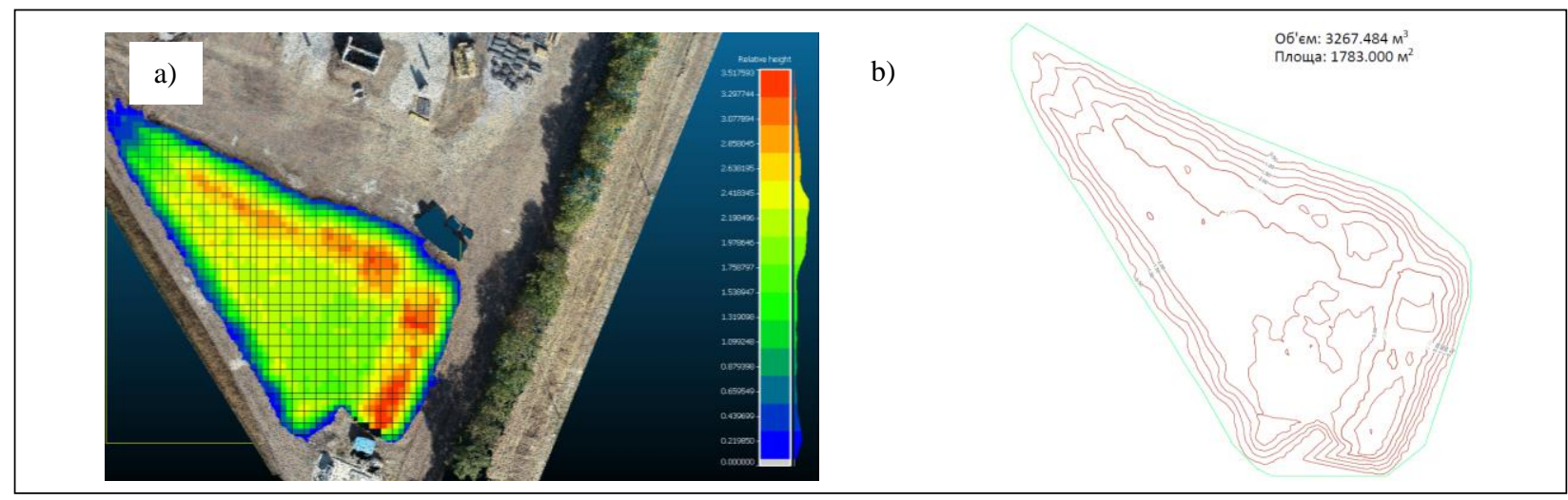

Figure 7. Testing area S3: a) 3D models overlaying; b) contour map

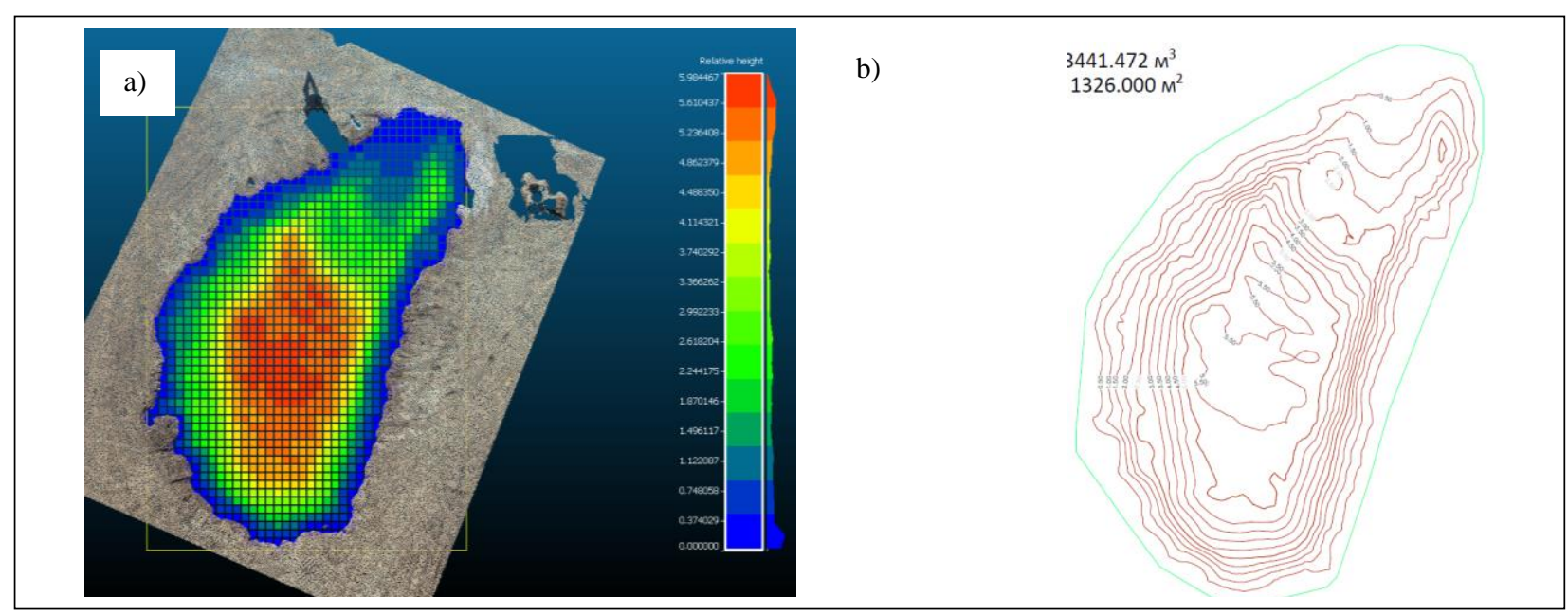

Figure 8. Testing area S4: a) 3D models overlaying; b) contour map

The results yielded some interesting findings. Although the sample for this study consisted of four values that are not enough for statistical infer, one may observe no correlation between the volumes and volumes errors. Volume differences fall into the allowable range of $4 \%$. Positive and negative values are both possible. Besides these figures, it is worth mentioning some technical aspects. The field surveying time took 40 minutes. The post-processing lasted 40 minutes for Agisoft Metashape and 30 minutes for PhotoModeler. This difference is due to the distinct number of generated points (less in PhotoModeler). The volumes' comparison held up to 40 minutes. These findings provide strong evidence in favor of UAV technologies. 
Table 6. The comparison results

\begin{tabular}{|c|c|c|c|c|}
\hline Software & \multicolumn{4}{|c|}{ PhotoModeler } \\
\hline Testing area & $\mathrm{S} 1$ & $\mathrm{~S} 2$ & $\mathrm{~S} 3$ & $\mathrm{~S} 4$ \\
\hline Area, $\mathrm{m}^{2}$ & 3644 & 1092 & 1341 & 1799 \\
\hline Volume, $\mathrm{m}^{3}$ & 13702.9 & 2460.9 & 3409.7 & 3389.6 \\
\hline Software & \multicolumn{4}{|c|}{ Agisoft Metashape } \\
\hline Area, $\mathrm{m}^{2}$ & 3669 & 1079 & 1326 & 3267.5 \\
\hline Volume, $\mathrm{m}^{3}$ & 13897.8 & 2448.3 & 3441.5 & 122.1 \\
\hline$\Delta V, \mathrm{~m}^{3}$ & -194.9 & 12.6 & -31.8 & 3.7 \\
\hline$\Delta V, \%$ & 1.4 & 0.5 & 0.9 & 3 \\
\hline
\end{tabular}

\section{Conclusions}

In this paper, we have put forward the claim that UAV technologies are the best choice for excavation works monitoring. This study draws on research conducted for warehouses construction. The primary goal of the study was twofold. The first was to estimate the UAV data accuracy; the second was to check and compare the quality and effectiveness of Agisoft Metashape and PhotoModeler software. The UAV DJI Phantom 4 has been used for data gathering. Data were uploaded to different photogrammetric software and processed automatically to generate dense point clouds. Six ground control points were surveyed by GNSS to transform the point clouds from the global coordinate system to the local coordinate system. This transformation allowed assessing the UAV data accuracy. Despite the different results for two software, the total root mean square error was in allowable range and deviated approximately in a range of $7 \mathrm{~cm}$. This is an underlying argument in favor of using UAV technologies for excavation works monitoring. The generated 3D models have been compared with each other in CloudCompare software to reveal the quality of Agisoft Metashape and PhotoModeler data. The comparison revealed the sufficient accuracy of UAV data for excavation works monitoring. It was found out that it is better to process data using PhotoModeler software that allows performing in-depth data analysis and blunders searching. Further research in this area should include an in-depth study of camera calibration and a detailed analysis of automatic approaches for point clouds generation.

\section{References}

Ai, M., Hu, Q., Li, J., Wang, M., Yuan, H., \& Wang, S. (2015). Robust Photogrammetric Processing Method of Low-Altitude UAV Images. Remote Sensing, 7, 2302-2333. https://doi.org/10.3390/rs70302302

Bosak, K. (n.d.). Secrets of UAV photomapping. CNES. http://s3.amazonaws.com/DroneMapper_US/documentation/pteryxmapping-secrets.pdf

Colomina, I., \& Molina, P. (2014). Unmanned aerial systems for photogrammetry and remote sensing: A review. ISPRS Journal of Photogrammetry and Remote Sensing, 92, 79-97. https://doi.org/10.1016/j.isprsjprs.2014.02.013

Hao, W., Zhang, Y.-H., \& Yang, H.-M. (2016, May). Topographic study on application of aero-photography and remote sensing systems by unmanned aerial vehicle in mapping of Gansu West Plateau mining area. Paper presented at the FIG Working Week 2016. Christchurch, New Zealand.

Henriques, M., Braz, N., \& Roque, D. (2015, May). Point clouds and orthomosaics from photographs their use in a civil engineering laboratory. Paper presented at the FIG Working Week 2015. Sofia, Bulgaria.

Isola, A., Shattri, M., Biswajeet, P., \& Helmi, Z. (2015, May). UAV - based imaging - digital elevation model extraction. Paper presented at the FIG Working Week 2015. Sofia, Bulgaria.

Mostafa, M. M. R. (2017). Accuracy assessment of professional grade unmanned systems for high precision airborne mapping. The International Archives of the Photogrammetry, Remote Sensing and Spatial Information Sciences, Vol. XLII-2/W6, 257-261. https://doi.org/10.5194/isprs-archives-XLII-2-W6-257-2017

Sadikin, H., Suwardhi, D., \& Gumilar, I. (2019, April). Topographic mapping using unmanned aerial vehicle (UAV) technology photogrammetry method. Paper presented at the FIG Working Week 2019. Hanoi, Vietnam.

Sadikin, H., Saptari, A. Y., Abdulharis, R., \& Hernandi, A. (2014, June). UAV system with terrestrial geo-referencing for small area mapping. Paper presented at the FIG Working Week 2014. Kuala Lumpur, Malaysia.

\section{Notations}

\section{Variables and functions}

$V_{\text {Photo }}$ - volume determined by PhotoModeler;

$V_{\text {Agisoft }}$ - volume determined by Agisoft Metashape.

\section{Abbreviations}

UAV - unmanned aerial vehicle;

GCP - ground control point. 